\title{
Traditional Isan Literature and Its Influence on Everyday Society
}

\author{
Kasorn Sansak ${ }^{1}$, Somchai Lamduan ${ }^{1} \&$ Sitthisak Champadaeng ${ }^{1}$ \\ ${ }^{1}$ The Faculty of Cultural Science, Mahasarakham University, Maha Sarakham Province, Thailand \\ Correspondence: Kasorn Sansak, The Faculty of Cultural Science, Mahasarakham University, Khamriang \\ Sub-District, Kantarawichai District, Maha Sarakham Province 44150, Thailand. E-mail: ksansak133@gmail.com
}

Received: April 21, 2014 Accepted: May 16, 2014 Online Published: June 2, 2014

doi:10.5539/ach.v6n2p87 URL: http://dx.doi.org/10.5539/ach.v6n2p87

\begin{abstract}
This investigation aims to analyze the traditional literature of North-eastern Thailand and discover how it influences everyday society. Drawn from a qualitative combination of documentary analysis, observation and interview, the research results show that the body of folk literature in this part of the world provides instruction for appropriate social behaviour. Based on firm Buddhist principles, the literature gives advice in four areas: society and administration, religion, family and education. This advice is incorporated into everyday society in the form of oral communication, the written word and entertainment in order to teach the next generations of society.
\end{abstract}

Keywords: traditional literature, influence, morals, customs, instruction

\section{Introduction}

The values and culture of North-eastern Thailand are a result of the application of instruction from traditional literature. Thai society is based on the principles of Buddhism but these valuable teachings were once inaccessible to the laity because of language and education barriers. It was the oral tradition of the community that enabled the common people to hear, discuss, adopt and transmit this wisdom (Rueangsuwan, 2006). Over time, local North-eastern Thai folklore has been combined with the influence of Khmer and Indian cultures to create distinctive, imaginative stories to entertain and educate the people. The stories take the form of the Buddhist Jataka and, on occasion, have been recorded to create a body of literature unique to the area (Bunnotok, 1982). This literature is the social mirror that both reflects the culture of the community and influences its development.

Culture is essentially the practices and thoughts performed by individuals in everyday community life (Apel \& Camozzi, 1996). This includes traditional knowledge, folklore, beliefs, art, customs and behaviour (Samutwanit, 1997; Suananon, 1977). Literature in North-eastern Thailand reveals these aspects of society and exposes the true principles of its people (Pinitpuwadon \& Kanjanawan, 1977).The content of the literature is then used, consciously or otherwise, to mould future generations. This is why North-eastern Thai stories are of interest to folklorists and social scientists. In order to understand the impact of traditional literature on society, this article explores the body of folklore in North-eastern Thailand and its impact. The paper first summarizes the content of folklore in the North-eastern region of Thailand, familiarly known as the Isan region, before discussing the forms of its influence on everyday life. The overriding sentiment is that traditional folklore has influenced society immeasurably in this part of the world.

\section{Literature Review}

Montri Dramote (1985) argued that the value of folk literature to the community is the same as national literature to the nation. Dramote concluded that folk literature is central to explaining the history and development of communities and ethnicities.However, it is important to realize the influence that the author or recorder has had on the delivery of the story (Wongkun, 1997). William Irmscher (1975) identified seven areas of influence that literature has on humanity.Firstly, Irmscher argued that literary characters enable people to see the different concepts of people and human reaction to them. Secondly, the creation of behaviour and events in literature teach people how to control circumstance with their actions. Thirdly, the creation of settings in literature enables people to see detail in their own lives. Fourthly, the structures and format of literature encourage deep feeling. Fifthly, from the language, symbols and imagery used in the literature, people may compare beauty and ugliness. Sixthly, the tone of the literature provides entertainment. Finally, literature provides people with examples of how to behave in different situations so that they may know the causes and solutions to problems. 
Although there has been little research concerning the influence of traditional Isan literature on society, a number of studies have been conducted within Thailand more generally about Isan folklore. These investigations have mainly centred on the influence of Buddhism (Prabnok, 2009; Wachiro, 2010) and the fundamental principles of Isan folk literature (Buahome, 2005). The content of the folklore has the characteristics of Jataka tales not found in the Pali canon. These chadoknoknibat aim to teach people in two main ways: how to behave with good morals and how to behave according to conventions and customs. They concern the life of a householder and their daily activities. The lead characters take a wide variety of forms and the text is written in the vernacular with figures of speech, phrases and idioms. Written in elegant, poetic language, Isan folklore is designed to stimulate the imagination of the reader and used by Isan people to shape social behaviour and control society (Attamarat, Intorntang \& Kanawset, 2006).

Thai scholarship is very much in agreement as far as the value of literature is concerned (Fakkong, 1987; Manyaporn, 1979; Mutramata, 1974; Tangkawee, 1985). There is value on nine principal fronts: emotion, knowledge, art, culture, history, imagination, critical thinking, use of language and inspiration. TawatBunnotok (1984) placed these categories into two groups: value for individual people and value for creative society. The significance of literature for society is largely due to its intertwined relationship with society. Literature is a vision of society that is both influenced by and influences it (Bunkajon, 1980). Traditional Isan literature is a reflection of everyday life because everyday life has been built upon it (Kuntawee, 1986). The literature is valuable for society because it reveals the lifestyle of Isan people, teaches a sense of duty to adhere to customs, to worship diligently, to be charitable and maintain the Buddhist precepts so to achieve good results in this life and the next (Kuntawee, 1986). Given the multi-faceted relationship between traditional literature and society, the research hypothesis for this article was that folk literature has influenced society by a variety of methods.

\section{Methodology}

This was a qualitative study that took place between October 2012 and October 2013, using both documentary research and field investigation. With the objective of analyzing the nature of instruction in Isan folk literature and its impact on society, the research team purposively selected ten texts for study. The texts chosen were Thamada Sonlok, Suwannajak Kuman, Thaw Khamson, Siao Sawad, Suwannasam, Phaya Khankhak, Inthiyan Sonluk, Puya Sonlan, Sangsinchai, Tamnan Meuang Fa Daet Songyang. These pieces of literature share two precise characteristics. Firstly, they are ancient recordings of oral tradition that have been inherited over time, whose sayings and teachings have become an integral part of the modern Isan language. Secondly, they are creative and poetic compositions of Buddhist principles that are suitable for use in educating society. The research area was chosen using a purposive sampling method by highlighting three provinces in North-eastern Thailand that were representative of Isan society and had a long history. The three provinces selected for the research were Roi-Et, Kalasin and Maha Sarakham. The research population was composed of the inhabitants of the three provinces in the research area and a sample of ninety individuals was purposively selected to provide data for the investigation.

The history and background of the ten texts was investigated by documentary research. The information was collected and separated by text. Further data was then gathered in the field by participant and non-participant observation, structured and non-structured interview and focus group discussion. The structured interview was divided into two parts. Part A asked for personal data about the respondent. Part B asked for examples and opinions on the influence of folklore on society in four key areas. The four areas were: 1) society, politics and administration; 2) religion; 3) education; 4) family. Data was validated using the triangulation methods of Supang Chantavanich (2009; Chantachon, 2006) and analyzed following the holistic methods of NgampitSatasongwon (1995; Chantachon, 2006), which included two processes: analytic induction and typological analysis. The three typologies chosen for analysis were knowledge, process and management. Knowledge means the base language taken from the texts and used in society. Process means the area the language was used in society: 1) society, politics and administration; 2) religion; 3) education; 4) family. Management means new information derived from use of the traditional literature and the results of integrating traditional literature in society.

\section{Results}

Isan literature is derived from the relationships between two sets of people or between people and their surrounding environment. The literature reflects the philosophies, morals, politics and society of local Isan culture. These principals have been inherited over time and comprise the current identity of Isan people. Aspects of this identity have also been drawn from proverbs in the literature, particularly Thamada Sonlok, Suwannajak 
Kuman, Thaw Khamson, SiaoSawad, Suwannasam, Phaya Khankhak, Inthiyan Sonluk, Puya Sonlan, Sangsinchai, Tamnan Meuang Fa Daet Songyang (Table 1).

Table 1. Sources of texts chosen for this investigation

\begin{tabular}{|c|c|}
\hline Literature & Background and source \\
\hline Thamada Sonlok & $\begin{array}{l}\text { Thamada Sonlok has been printed since } 1969 \text { in Wat PhonpanaoWiangjan, in Thai and } \\
\text { Lao languages. During this investigation, only the Thai version was studied (Suksai, } \\
\text { 1999) }\end{array}$ \\
\hline Suwannajak Kuman & $\begin{array}{l}\text { Suwannajak Kuman was first recorded in } 1906 \text { at Ban Ta Toon, Ta Toon Sub-district, } \\
\text { City District, Maha Sarakham Province by Prabatkanan Samanaenputlaeprapa, the } \\
\text { document is kept in Mahasarakham University Library (Prabatkanan, 1906) }\end{array}$ \\
\hline Thaw Khamson & $\begin{array}{c}\text { Thaw Khamson was given to Ariyanuwat (Ari Khemjari) Mahachai Temple, } \\
\text { Mahasarakham City in } 1970 \text { (Bunnotok, 1983). }\end{array}$ \\
\hline Siao $s$ & $\begin{array}{l}\text { It is unknown when Siao Sawad was written but its origin is over } 300 \text { years ago } \\
\text { (Weerawong, 1961) }\end{array}$ \\
\hline Suwannasam & Suwannasam is of unknown origin (Pramahaphummiklik, 2004) \\
\hline Phaya Khankhak & $\begin{array}{l}\text { Phaya Khankhak is found in all temples, including Wat Klang, Kamalasai District, } \\
\text { Kalasin Province and WatKamriang, Kamriang Sub-district, Kantarawichai District, } \\
\text { Maha Sarakham Province (Wongoowan, 1982). }\end{array}$ \\
\hline Inthiyan Sonluk & $\begin{array}{l}\text { Inthiyan Sonluk was transcribed by Napaporn Pimwornmethakoon in 2005. It was first } \\
\text { created during the reign of Sourigna Vongsa of the Lan Xang Kingdom in the } 17^{\text {th }} \\
\text { Century (Pimwornmethakoon, 2005). }\end{array}$ \\
\hline Puya Sonlan & $\begin{array}{l}\text { Puya Sonlan was transcribed by Pramuan Phimsen and Thongmak Siphum in } 2008 \text { for the } \\
\text { Centre for Inheritance of Traditional Knowledge in North-eastern Thailand (Phimsen \& } \\
\text { Siphum, 2008). }\end{array}$ \\
\hline Sangsinchai & $\begin{array}{l}\text { Sangsinchai was created by Tawangkam, probably a person of the royal court in the reign } \\
\text { of Sourigna Vongsa of the Lan Xang Kingdom (Pra Ariyanuwat, 1988). }\end{array}$ \\
\hline $\begin{array}{l}\text { Tamnan Meuang Fa } \\
\text { Daet Songyang }\end{array}$ & $\begin{array}{c}\text { Tamnan Meuang Fa Daet Songyang derives from the deeds of Anawrahta Minsaw, the } \\
\text { first ruler of the Pagan Empire (Pra Ariyanuwat, 1975). }\end{array}$ \\
\hline
\end{tabular}

These ten scripts are the sources of proverbs that teach people how to behave appropriately in their everyday lives and instil lifelong knowledge. They are written in the form of rhyming poems and reveal awareness of living together with people in society by using Buddhist and ancestral teachings as the foundation of everyday life. The content of each of the ten pieces of folk literature studied is used as the basis of social behaviour so that people can achieve happiness and peace. The proverbs are used as tools to generate wisdom and ensure that people in society are good and behave appropriately. Each piece of literature places different levels of importance on different issues and has unique focal points. There are four distinct groups of social teachings, which are society and administration (directors teaching sub-directors, elders teaching the youth and leaders teaching subjects), religion (monks teaching locals) education (teachers teaching pupils, local wise-men teaching locals) and family (parents teaching children, grandparents teaching grandchildren and husbands and wives teaching one another).

\subsection{Excerpts from Isan Literature Concerning Social and Administrative Instruction}

"Meua nan pragohmee jai dang nai tam tukchaokam

Seen baetwainaineuabawlao long dailaew

Hoi-et huamueang kaowan tataosuay

Pragaw song sang haikamhoosoo an

Bat nee boon haodai ben paya tum prai

Jao tang buang ma on nawmkaw kaochuaihai dang nee" (Thamada Sonlok) 
['At that time monks had an established moral mentality by strictly adhering to the eight Buddhist precepts. All of Roi-Et city who paid tribute to the monks would be taught about moral practice. Now, the cumulative merit has allowed them to become governors. People from other provinces come to ask for favour by offering tributes of gold to the monks.']

"Kagaw ben settitao leucha changao

Ngeunkambaetsip go tae konglonaneknong

Ayooyeunmak lonleuayinglai bee

Yoo tang kin tan baisoo wan bawmeehai" (Thamada Sonlok)

['He is a famous, wealthy older person. He has a lot of money and a long life, with much more to come. He eats and makes merit every day and will have no problem.']

"Pen poo taohaihak look lanlaen

Pen koonkwan haihakkanmueang ban

Somsatanbueanghuenghomtuantua

Yadaihak ping poon sang pee bawdee" (Siao Sawad)

['People must love their children. Governors must love their city, lead their city to peace and happiness, not be biased to those they love or hate.']

"Pen jaohaihakprai ponmueang

Pen naikon hakkon muan poo

Aykotaipaeng lanhoom haw

Kwan paw ban kookon" (Phaya Khankhak)

['Rulers of a territory must love their subjects. They must love the people under their rule. Elders must love their children and grandchildren. Village chiefs must love their villagers.']

"An nuengyadaibreuksaduay akomsilpasat nan neu

Maenwa hoomaknoi jam waiyakaipraheuy

Nail lok tae tukyueangying chai

Hai koi paeng ton haokwakon tang kai

Krongsilpananmueangplaeng yam ying

Tong haihakwa kaokonglon look meeyapraheuy

Satjanan yang noon ben brayot" (Sangsinchai)

['Do not study magic and the dark arts. If you know about them, then remember and do not speak of them. In this world, men and women suffer equally. Care for yourself more than others. Care for the arts of your city. Care for your wife and children. Promise to be charitable, faithful and worthy.']

Isan literature teaches people to know right from wrong and that honest work is a prerequisite for prosperity. According to the tales, morals and only morals put people at peace. If people do not have morals, they will have no reason for being. Long lives are thus reserved for the virtuous, a character obtained by making merit. For this reason, when people have enough to live and eat, they must learn the satisfaction of giving to the less fortunate.

Administrative advice is common in the traditional literature of Isan. The recurring message is that people in high authoritative roles, must take full responsibility for those roles. They must be fair, just and rule over their subjects with peace and happiness. Rule should be achieved through love; kindness must be displayed more than power. The literature stresses that disposition, leadership and a place at the head of the family do not necessitate vanity. If you possess knowledge, you must keep it for the right moment. Ultimately, the literature suggests that all people in this world suffer equally, so humans must use their knowledge to care for their own houses.

\subsection{Excerpts from Isan Literature Concerning Religious Instruction}

"Doi dang nokeeiang kin makpohai

Saewsaewsiangbawmee to hong

Saewsaewhong to diawmeud moo 
Gawhak boon briabdaidoidan dang diaw" (Siao Sawad)

['It's like an eagle perching on a branch eating ripe fruit of the Bodhi and Banyan trees. It is loud but nothing can be seen to make the sound. Only one bird screeches but the sound is as though they all screech.']

"Tae nan prom phayakroot prom phayanak tang lai

Dee gae song phayahak taw kan bang nan

Gawpeua poon pa taw somparn pang kawnjinglaew

Sat yoodai loom fabaw tam haikaekan tae dai" (Phaya Khankhak)

['At that time, King Toad and the Queen Naga were in love under the power of merit. This was a time when animals under the same sky did not harm one another.']

"Yang meekonohaingua pong paed

Ma tiawka kin poo moo kon" (Siao Sawad)

['There was a bad cow that sinned and ate the people of this town.']

"Meua nan prajeung deunnakhaigae ploy phayataen

Tae nan nakoleuy ploy taenwangwai" (Phaya Khankhak)

['The King Toad told the Queen Naga to release the Lord Angel and the Queen Naga did as requested.']

"Pen phaya jaochang yang dai yang tang teen

Pen inprom yang dai long chai chat

Hedwasongsarn nee anijangtaotua

Ha bawmeetiang man doidai tang jai" (Siao Sawad)

['Even if you are the owner of an elephant, you must sometimes walk. Even Brahma and Indra must be reborn. Pity them in this life, for alas it's not stable and cannot be as they wish forever.']

The Isan literature teaches that some people perform good deeds when searching for merit. When there is a positive result, all people benefit. When there is a negative result, all people suffer. Through the results of good deeds or merit people can be friends when they were once enemies. When desire enters the minds of people it will turn this good to bad, especially anger, and cause the people to lose their sensibility. In light of this, people must be compassionate and merciful. Nothing is ever certain and people cannot always do what they want.

\subsection{Excerpts from Isan Literature Concerning Educational Instruction}

"Sood tee maenam kwangkeufa paw klaijaoheuy

Tae nanlai wan dailaikeunkraoteebpailaew

Meuaseub meuanandaikuab pee jaoheuy

Kaw jeungmeauhodfa cheuwa meuangtaen tee poon" (Puya Sonlan)

['It took a full year for the King Toad and his followers to get to heaven through true dedication and determination. They did not give up or retreat because it was difficult. This allowed them to successfully reach heaven.']

"Anneung yam noomnoihai ham hienkoon

Lang tuea boon haomeeyossoopiengfa

Pai tang na pen nai chai peun

Kranwakwanhoonoikaokeunkeehao" (Siao Sawad)

['When you are a child and study different subjects, if you possess merit, you will become a boss and have a high position. If you know little, others will take advantage.']

"Annuengkran yak hooya man nawn lap

Kran yak hen man tieawpaiyiem

Meesahaihaipai ha ma wae

Yadaikoongeun kaewpeuanfoong” (Siao Sawad) 
['If you want to know, don't sleep. If you want to see, you must visit often. If you have friends, go to see them. Don't borrow money from your friends.']

Traditional Isan literature advises people to never give up. In the face of difficulty, persevere and success will follow. Knowledge and lessons are things that teach people to take advantage of society. Knowledge is a source of prestige, fame and wealth. In addition, the body of literature teaches that people must be diligent and not lazy, people must listen wide and see far, people must be considerate, respectful and not impose themselves on friends. Professionally and educationally, help must first come from within. The literature trains people to use their own experiences and not overlook the things that monks, experts or parents have taught.

\subsection{Excerpts from Isan Literature Concerning Familial Instruction}

"An nuengjakklao tan hai koi pienja

Jakhednahai man pienkokkao

Tam suanhai poon plaeng pawn foon

Yak gawhai yak tae noiyalon leunpraman" (Siao Sawad)

['If you are going to talk about something, do so gradually. When you work a rice farm, put your heart into it. When you tend to an orchard, be persistent in watering your plants and loosening the soil for the fertilizer. If there is something you want, let wanting be sufficient.']

"Yadaiyaiyab tee kanna

Kong pai man hakhuangdoi dam

Yadaikan tom tin ad hoonamawkbaw

Paeng wait a plengkao nahuahaisuan" (Siao Sawad)

['Refrain from moving your borders to intrude on others' land because everyone's land is their own. Do not turn off the water just to drain your own field.']

"Annueng jak yang yai long jakkeha

Jong kaningnaikeud ham hondeetuan

Kranwakarn pain an meedeekwayoo

Jong heebfaopaitawnyanan" (Siao Sawad)

['If you are going to leave home, think carefully first. If you think that leaving will have a greater benefit than staying, then go. But if leaving will cause more problems than staying, then don't go']

Isan literature teaches people to use polite vocabulary because politeness is one way to reveal a calm manner and sincerity. People must learn to love and be satisfied by their status of being. People must not aspire to things out of their reach and should know their limits. In Isan literature selfishness is portrayed as a grave social ill. People should realize that the benefit of cooperation and social peace is greater than the benefit of privacy.

There are many examples of exploitation in traditional Isan literature. A recurring theme is instruction for married couples and how they should treat one another. In their lives together, the wife and husband must be honest and strong. They must know how to suppress their feelings and be patient. They must soothe and pamper one another and be sympathetic towards one another.

There are eight major concepts in traditional Isan literature:

1. Isan literature emphasizes that human nature is essentially good. The reason for immorality and depravity is caused by the surrounding environment and misguidance. So the literature acts as a restraint, pulling people back from evil paths by teaching basic values and correct behaviour.

2. Isan literature teaches ideal relationships in the family and clearly defines roles for each member.

3. Isan literature teaches leadership values to prevent resentment on both sides. Leaders can go far if their subjects are good.

4. Isan literature reveals male and female values, teaching females and defining their roles more than males. This was because in the past the females stayed at home and were readily blamed for social problems.

5. Isan literature reveals values between generations with the objective of teaching children the importance of gratefulness towards their ancestors, especially their mother, father and grandparents. This teaches children to be modest, humble, well-mannered and obedient. 
6. Isan literature reveals the importance of nature and the relationship between humans and the environment by teaching people to respect and adapt to nature, especially spirits with the power to cause prosperity or sorrow in humans.

7. Isan literature teaches values of friendship and human relationships. The literature also emphasizes the characteristics of harmony, unity and mutual assistance in society. Examples of this are helping one another to build houses or harvest rice. The literature advises people to work together for community initiatives and ceremonies, with all people working for the same goals.

8. Isan literature reveals the teachings of morals, karma and sin in Buddhism with the objectives of teaching people to do good deeds, refrain from evil and maintain a clean mind.

\subsection{Influence}

In this section, results of respondent interviews are descriptively presented to reveal the impact of Isan literature on everyday society.

The influence of the literary concepts on Isan society is achieved through the media of sermons, school curriculum textbooks, Mor Lam performance, stories from grandparents and cultural activities. "In the past, Isan people were illiterate and the oral tradition of the literature was a convenient and effective way to educate them. In this way it was remembered and in this way it was transmitted from generation to generation." (Tongpoon Sripongsert, personal communication, 2013). Now the traditional instruction "is an excellent way of integrating ancient lifestyle and customs into modern society" (Prarat Preechamoonee, personal communication, 2013) because they are represented in the form of external media and in full view of the public.

Mr. Boonrueang Tawornsawat, a Thai artist with the alias Titkaew Truattalat (personal communication, 2013), suggested that Thamada Sonlok fosters care "in every aspect of our lives. We use it to teach couples how they must behave towards one another" for a happy and successful union. "If people do not act according to moral values, Isan people reserve the phrase "kalam." Isan instructional literature is deep-rooted in society. Mr. Tawornsawat also said that "Sangsinchai is a story used by many Thai artists as inspiration for their work because is it one of the most familiar ancient tales with the Thai people and is already incorporated into popular culture, in the form of Mor Lam productions." Aside from this, "Sangsinchai is integrated in education and used to teach local people" (Prakru Siripattanonitet, personal communication, 2013).

In fact, a number of the literary concepts are used in the education system. Under the Thai national curriculum of 2001 (Ministry of Education, 2001), Suwannasam was incorporated into the primary grade one curriculum. The literature was integrated into study textbooks, two examples of which are Social Studies, Religion and Culture (Manklamanee \& Ruamsuk, 2012) and Buddhism (Ketklangdon \& Jaturapakoon, 2001). The books include explanation of morals and values that young children must employ in their everyday lives.

Chairman of the Roi-et Provincial Culture Office, Dr. Satit Kritalak (personal communication, 2013), clarified how local people understand this body of literature as being "extremely old, yet having a huge influence on Isan customs." The literature also has an influence on working practices and is read to the family at ceremonies and in everyday life. The literature is read in both the original language and in modern Thai to people in the local community, who believe that, as a result of listening, their wishes will be fulfilled. "However, their wishes will only come true if they rigorously observe the Buddhist precepts beforehand." Chairman of the Mahasarakham Provincial Culture Office, Dr. Pornchai Srisarakham (personal communication, 2013) asserted that "the content of the literature has been transformed into the values of the people." These beliefs are the founding principles of Buddhism and, as such, they have enabled ordinary people to become good Buddhist citizens by giving people confidence in the human ability to be taught. Moreover, by obeying traditional literature, people are given a platform to practice Buddhism.

Dr. Thonkorn Cheujamroon (personal communication, 2013), the head of the Education, Religion and Culture Organization of Kalasin Province, attested that "education enables people to live their lives in the right way. In order to instruct them correctly, Buddhism and personal development by social instruction are the two most important things that allow this. There is a local saying: "people are animals that achieve excellence through training." Mr. Wichai Singphromsarn (personal communication, 2013) said that it is important to control behaviour so that it is appropriate for the surrounding environment. "This is achieved in Isan by practice according to traditional literature."

"Suwannajak Kuman derives from Buddhist teachings and was influenced by and is revealed in the Isan customs of heet 12 klong 14," (Wittaya Wongkalasin, personal communication, 2013) which is how it and the other literature have been so seamlessly adopted by Isan society. Mr Sook Yubonchoo (personal communication, 
2013), an officer at the Kalasin Provincial Culture Office, felt that "if a mind is in need and the mind treats behaviour as its tool to achieve that need, then behaviour is the thing that gives the mind happiness." Isan people view appropriate and moral behaviour as a way to achieve happiness and so use traditional literature as part of oral communication to harness that phenomenon.

According to Mr. Banyat Sawaengdee (personal communication, 2013), people in power have two responsibilities: to assert their authority justly and love and care for their people. "Thamada Sonlok teaches exactly this, which is why it is used as an example for the family, community, society, region and nation." Mr. Weerachai Kamhonsa (personal communication, 2013), director of the Kalasin Province Culture Bureau told of how the adult characters in Thamada Sonlok were "considered mature by Isan society and had reached an advanced point in life with unexpected gain, reputation, admiration and happiness." They have extensive social experience. "The instruction of Thaw Khamson is integrated into the lives of Isan people in many ways, especially through the culture of the marriage ceremony and the traditional blessing given to the newlyweds." (Boonma Sripongsert, personal communication, 2013). Thaw Khamson is used to teach newlyweds how to treat one another by providing them with knowledge from experiences that they do not yet have.

From the research data gathered during this investigation, three clear categories can be determined to describe the influence of Isan literature on society: 1) use in oral communication; 2) use in written communication; 3) use in entertainment. These three methods of influence incorporate teachings under each of the four structures identified by the research: society, politics and administration, religion, education and family (Figure 1).

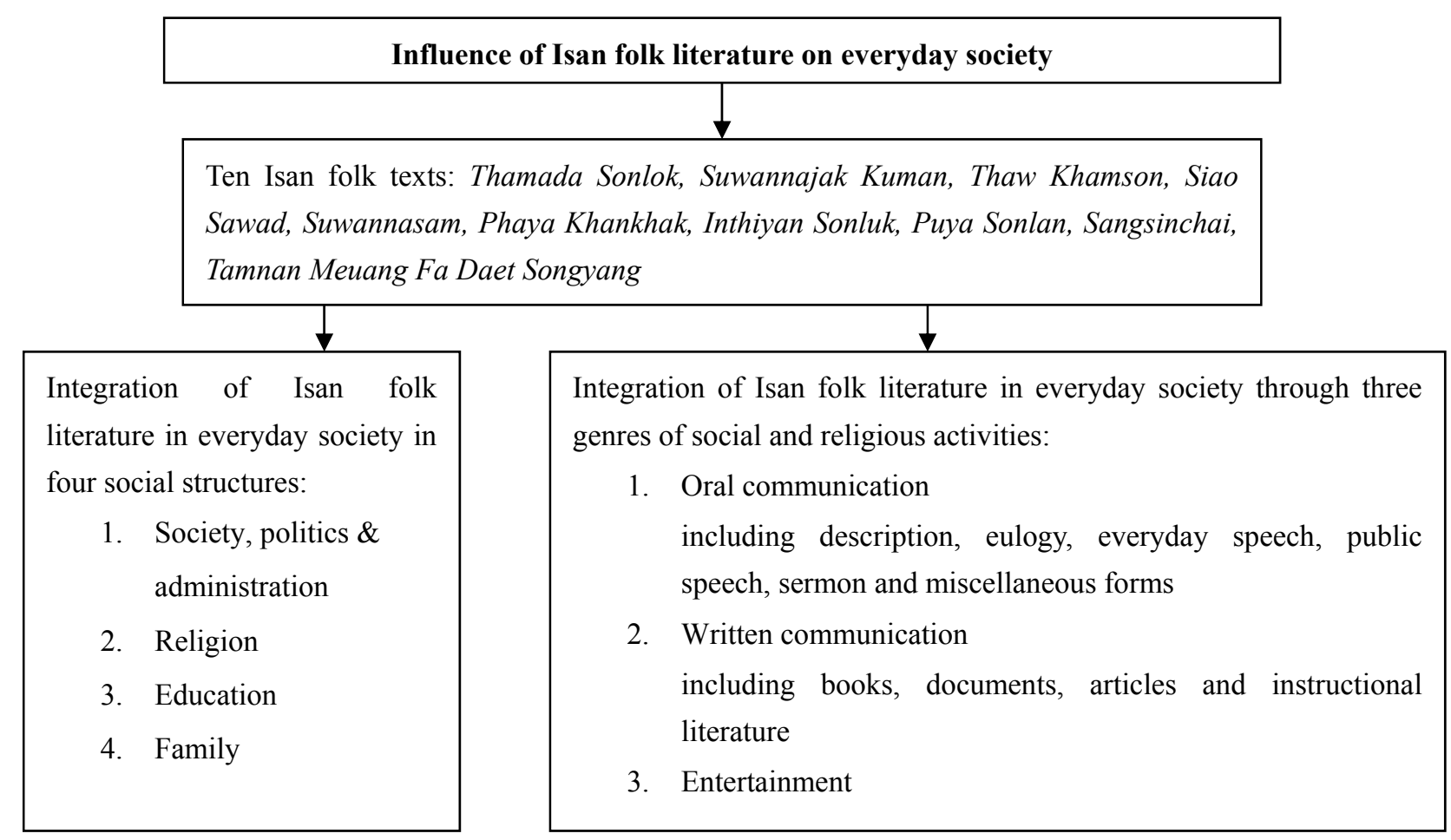

Figure 1. The impact of Isan folk literature on everyday society

\section{Conclusion}

Instructive literature was created in Isan for more than one reason, which is why there are many different types. The teachings have been inherited over time with the aim of teaching values and appropriate social behaviour. The Isan literature analysed in this investigation tells stories and tales that reveal much of Isan religious and social history about beliefs and lifestyle, fitting with the conclusions of Montri Dramote (1985). It must not be forgotten that these works are the creation of ancient poets for the purpose of entertainment, full of points to encourage thought. The tactics of the poetry are to make the meaning concise and direct.

The content of traditional Isan literature teaches people how to create a better life and world through such lessons as selecting a partner, taking care of husbands and being a good mother. Additionally, the works instil behaviour regarding customs and traditions, everyday life and socializing in Isan society. They create awareness of responsibility towards ethical behaviour in order to define roles for strengthening society in accordance with 
traditions and customs. In addition to the nine traditional areas that literature is considered to influence, social control must be added (Fakkong, 1987; Manyaporn, 1979; Mutramata, 1974; Tangkawee, 1985). Folk literature in Isan is extremely interesting for gender studies because, as Napaporn Pimwornmethakoon (2005) has investigated, the perceived responsibilities of males and females in society are clearly defined by the literature. Pimwornmethakoon's research into gender roles found that Isan communities have accepted the primary female function as that of a mother but these perceptions are being challenged by external influences. It is noted and regrettable that this aspect of Isan folklore cannot be further explored here due to the constraints of the investigation.

The ten pieces of literature studied in this investigation are tools for instructing behaviour in Isan society and teach people in four key areas: society and administration, religion, family and education. The literature is founded in the Buddhist religion, which adds to its value in a Buddhist society, and is integrated into society by three media: oral communication, the written word and entertainment. Ultimately, this is a body of work that continues to shape the behaviour of North-eastern Thai people.

\section{References}

Apel, H., \& Camozzi, A. (1996). Adult environmental education: A handbook on context and methods. Bonn: Institute for International Cooperation of the German Adult Education Association.

Attamarat, R., Intorntang, K., \& Kanawset, A. (2006). Morals in Isan folktales [in Thai]. Education Journal of Khon Kaen University, 29(2), 59-66.

Buahome, P. (2005). A study of the behaviour of Sritonchai in Thai literature [in Thai]. PhD thesis, Srinakkarinwirot University, Thailand.

Bunkajon, T. (1980). Folktales and Thai society, 1932-1957 [in Thai]. Bangkok: Sangsan.

Bunnotok, T. (1982). Local literature [in Thai]. Bangkok: Odeon Store.

Bunnotok, T. (1983). Feungwien: A study of the history and literature of Isan [in Thai]. Bangkok: Thammasat University.

Bunnotok, T. (1984). Methods for studying modern literature [in Thai]. Bangkok: Thaiwattanapanit.

Chantachon, S. (2006). Materials for teaching advanced cultural qualitative research [in Thai]. MahaSarakham: Research Institute of Northeastern Art and Culture.

Chantavanich, S. (2009). Qualitative research method (17th ed.). Bangkok: Chulalongkorn University Press.

Dramote, M. (1985). The history of Thai music: the essence of Thai music [in Thai]. Bangkok: Jaroenwittaya Publishers.

Fakkong, S. (1987). Thai literature before Western influence [in Thai]. Bangkok: Karnsasana Publishing.

Irmscher, W. (1975). The nature of literature: writing on literary topics. Dumfries, NC: Holt, Rinehart \& Winston.

Ketklangdon, P., \& Jaturapakoon, N. (2001). Buddhism [in Thai]. Bangkok: Prapansan.

Kuntawee.N. (1986). Study of the value of Siao Sawat [in Thai]. PhD thesis, Mahasarakham University, Mahasarakham.

Manklamanee, W., \& Ruamsuk, P. (2012). Social studies, religion and culture [in Thai]. Bangkok: Prasanmit Printing.

Manyaporn, K. (1979). Comparative literature [in Thai]. Bangkok: Pannakit.

Ministry of Education. (2001). Thenational curriculum of 2001 [in Thai]. Retrieved December 15, 2013, from http://www.arc.nrru.ac.th/be/data/cur.pdf

Mutramata, P. (1974). Thai literature: History and criticism [in Thai]. Ayutthaya: Tienwattana Publishers.

Phimsen, P., \& Siphum, T. (2008). The Puya Sonlan, Lan Son Puya instruction literature [in Thai]. Khon Kaen: Centre for Inheritance of Traditional Knowledge in Northeastern Thailand.

Pimwornmethakoon, N. (2005). Instruction literature from the poem Inthiyan Sonluk [in Thai]. Khon Kaen: Khon Kaen University.

Pinitpuwadon, S., \& Kanjanawan, N. (1977). General knowledge of Thai literature [in Thai]. Bangkok: Duangkamon. 
Pra Ariyanuwat. (1975). Tamnan Meuang Fa Daet Songyang [in Thai]. PraNakhon: Tammabannakarn Publishing.

Pra Ariyanuwat. (1988). Sangsinchai [in Thai]. Pra Nakhon: Tammabannakarn Publishing.

Prabatkanan Samanaenputlaeprapa. (1906). Suwannajak Kuman [in Thai]. Maha Sarakham: Tatoon Temple, Maha Sarakham.

Prabnok, P. (2009). A comparative study of the concept of Brahma in the Upanisads and the Suttantapitaka [in Thai]. PhD thesis, Silpakorn University, Thailand.

Pramahaphummiklik Boonta. (2004). Bodhisattava's ideology in the life and social development [in Thai]. $\mathrm{PhD}$ thesis, Thammasat University, Thailand.

Rueangsuwan, J. (2006). Good things of Isan. Memorial at cremation ceremony sponsored by the royal family for Mrs. Oranut Rueangsuwan, Wat Prasrimahatat Woramahawihan, Bang Kaen, Bangkok, Monday $27^{\text {th }}$ March, 2006 [in Thai].

Samutwanit, C. (1997). Three general characteristics of government and Thai politics [in Thai]. Bangkok: Sukumlaebut.

Satasongwon, N. (1995). Foundations of the humanities and culture [in Thai]. Bangkok: Chulalongkorn University.

Suananon, D. (1977). Lexicon of psychology [in Thai]. Bangkok: Odeon Store.

Suksai, M. (1999). Thamada Sonlok: Transcription from ancient Isan into Thai script [in Thai].Ubon Ratchatani: Moonmang Thai-Isan.

Tangkawee, S. (1985). Knowledge and skill in language [in Thai]. Bangkok: Odeon Store.

Wachiro, P. (2010). Analysis of the Buddhist perspectives in Phaya Khankhak [in Thai]. PhD thesis. Mahachulalongkornrajavidyalaya University, Thailand.

Wongkun, P. (1997). Dark ages and disaster in the Thai economy [in Thai]. Bangkok: Wittitat Program.

Wongoowan, P. (1982). Phaya Khankhak [in Thai].Maha Sarakham: Culture centre of MahaSarakham Province.

\section{Copyrights}

Copyright for this article is retained by the author(s), with first publication rights granted to the journal.

This is an open-access article distributed under the terms and conditions of the Creative Commons Attribution license (http://creativecommons.org/licenses/by/3.0/). 